\title{
Stator Shape Optimization for Electrical Motor Torque Density Improvement
}

\author{
Hea-Joong Kim, Hee-Deuk Jun, Youn Hwan Kim, Jae-Won Moon \\ Rotating Machinery Center / Korea Testing Certification \\ 22 Heungan-daero 27beon-gil, Gunpo-si, Korea \\ motor@ktc.re.kr; jhdeuk@ktc.re.kr; younhwan@ktc.re.kr; moon@ktc.re.kr
}

\begin{abstract}
The shape optimization of the stator and the rotor is important for electrical motor design. Among many motor design parameters, the stator tooth and yoke width are a few of the determinants of noload back-EMF and load torque. In this study, we proposed an equivalent magnetic circuit of motor stator for efficient stator tooth and yoke width shape optimization. Using the proposed equivalent magnetic circuit, we found the optimal tooth and yoke width for minimal magnetic resistance. To verify if load torque is truly maximized for the optimal tooth and yoke width indicated by the proposed method, we performed finite element analysis (FEA) to calculate load torque for different tooth and yoke widths. From the study, we confirmed reliability and usability of the proposed equivalent magnetic circuit.
\end{abstract}

Keywords: Torque Density, Power Density, Electric Motor, Stator structure, Equivalent Circuit

\section{Introduction}

As the electronics of today become highly efficient and precise, there are more demands and attempts to improve the performance via design optimization [1-2].

For electric motor design, deciding stator tooth and yoke width is cumbersome yet very important. When designed with inappropriate tooth and yoke width, the motor may not operate at its operation region due to flux density saturation of the yoke, and not reach the maximum torque for given tooth and yoke width due to lack of maximum Back-EMF. Thus, the proper tooth and yoke width must be selected for electric motor design. One of the most widely used methods for electric motor analysis is finite element analysis (FEA). However, FEA requires a number of component modelling, complex preprocess steps, and long analysis time [3-5].

Thus in this study, instead of suffering slight accuracy compared to FEA, we propose an equivalent magnetic circuit of stator, which allows fast and simple calculations for finding tooth and yoke width that optimize load torque [6-8]. Generally Back-EMF and load torque show the greatest values for the tooth and yoke width ratio that has the smallest magnetic resistance to magnetomotive force of permanent magnet. Therefore, to find the tooth and yoke width with minimum magnetic resistances for the number of slots per pole of concentrated winding electric motor and distributed winding electric motor, we formulated the magnetic stator resistance for one pole. Finally, we confirmed the reliability of the equivalent magnetic circuit method by comparing the optimal tooth and yoke width found by FEA and the equivalent magnetic circuit, and by the proposed method.

\section{Finding Optimal Tooth-Width/Yoke-Width Using Stator Equivalent Magnetic Circuit}

For electric motor design, when desired output power and current are decided as electric motor specifications, current density can be decided considering the cooling method, and once the current density is decided, wire diameter can be decided. The calculation of armature winding turn for the required Back-EMF is decided for voltage limit and magnetic flux per pole, and once armature winding turn is decided, the cross-sectional area slot can be determined considering the outer diameter of the stator given as an electric motor specification.

When rotor diameter is designed considering Torque per unit Rotor Volume(TRV), slot area and stator outer diameter are already determined and therefore, widths of the tooth and yoke cannot be increased by much. Therefore, it is necessary to find tooth and yoke width ratio that maximizes Back-EMF within the size restrictions. 
To optimize the tooth and yoke width, we formulated the equivalent magnetic circuit (EMC) of the stator core. To find the tooth and yoke width with the maximum Back-EMF and maximum torque, we found magnetic resistance of the stator. Since the magnetic flux on one pole flows to the neighboring poles on both sides, to simplify the calculation, flux path on both sides are not considered, but only the flux path though one side is considered for finding the magnetic resistance.

The assumptions for finding the magnetic resistance of stator are as follows:

1. Relative permeability of tooth and yoke is the same.

2. Saturation effects of tooth and yoke are not considered

3. Tooth tip is not considered.

4. The outer diameter and inner diameter of stator are determined by the initial shape.

Figure 1 shows the equivalent magnetic circuit formed by flux of each pole for distributed winding 6-pole 36-slot and concentrated winding 6-pole 9-slot.

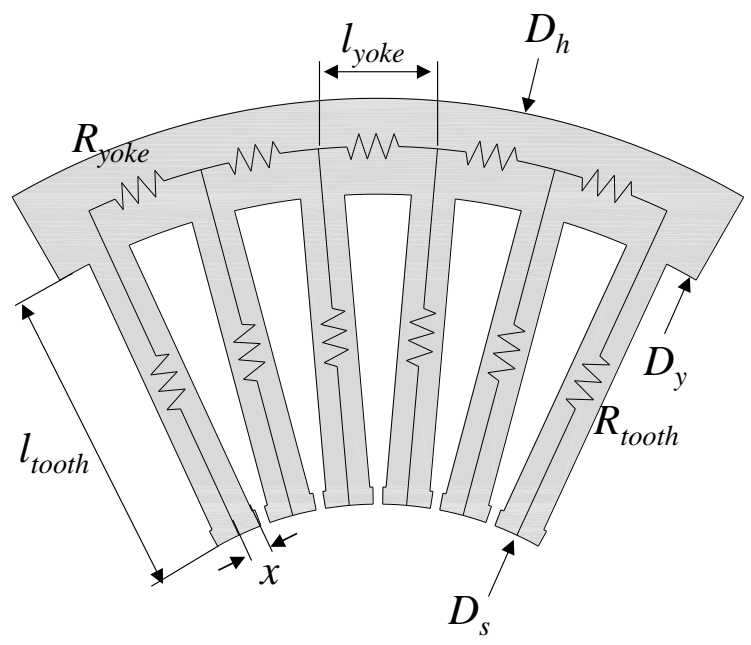

(a) Distributed winding

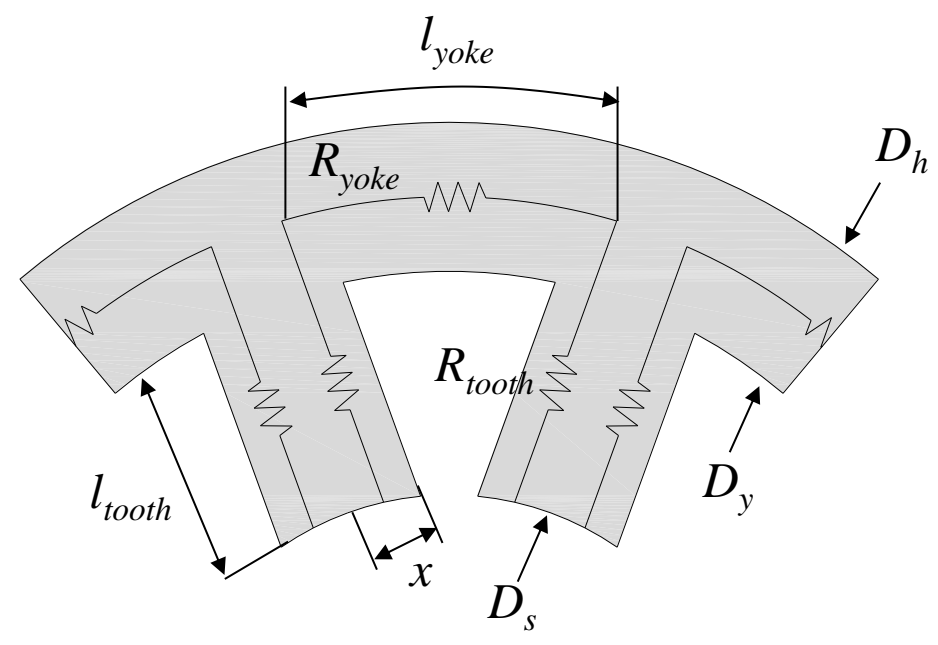

(b) Concentrated winding

Fig. 1: Equivalent magnetic circuit of stator.

The area for a slot can be formulated as the following:

$$
A_{s}=\frac{\pi}{4 n_{s}} \times\left(D_{y}^{2}-D_{s}^{2}\right)-x \times\left(D_{y}-D_{s}\right)
$$

$x$ represents a half of tooth width, $A_{S}$ the cross-sectional area of a slot, $n_{s}$ the total number of slots, $D_{y}$ the outer diameter of a slot, and $D_{s}$ the inner diameter of the stator.

For all analysis models, the slot areas have to be constant, and $D_{y}$ can be found using the root of $2^{\text {nd }}$ order polynomials.

$$
D_{y}=\frac{2 x n_{s}}{\pi}+\sqrt{\left(\frac{2 x n_{s}}{\pi}\right)^{2}+D_{s}^{2}-\frac{4}{\pi} n_{s}\left(x D_{s}-A_{s}\right)}
$$

For distributed winding, the equivalent magnetic circuit equation for magnetic resistance changes if different values are used for the number of slots per pole. Magnetic resistance for 3 slot per pole:

$$
R_{\text {total }}=2\left(\left(2 a^{-1}+b\right)^{-1}+a\right)^{-1}+b \quad a=\frac{1}{R_{\text {tooth }}}, \quad b=\frac{1}{R_{\text {yoke }}}
$$

Magnetic resistance for 6 slot per pole: 


$$
R_{\text {total }}=2\left(\left(\left(\left(\left(a^{-1}+b\right)^{-1}+a\right)^{-1}+b\right)^{-1}+a\right)^{-1}+b\right)^{-1}+b
$$

As the number of slots per pole increases, the magnetic resistance of equivalent magnetic circuit for stator shows in a long continued fraction. The magnetic resistance of the equivalent magnetic circuit for concentrated winding electric motor is as follows:

$$
R_{\text {total }}=R_{t}+R_{y}
$$

The magnetic resistance change for tooth widths change is shown in Figure 2.

Since the slot areas are the same, the yoke width decreases with tooth width increase and the magnetic resistance of stator changes accordingly. For tooth width increase, the magnetic resistance value first shows a steep drop, a relatively flat curve, and after a certain region, an increase again. From the figure, we can find the tooth and yoke widths which minimize the magnetic resistance.

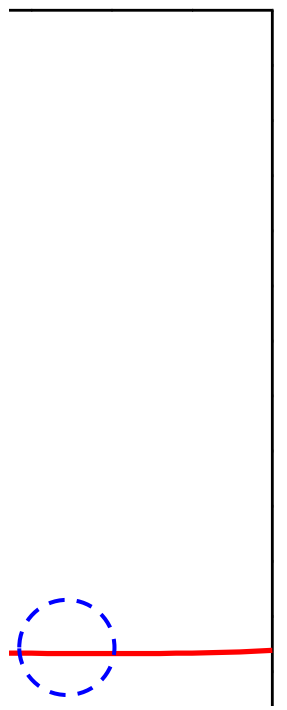

Fig. 2: Magnetic resistances (6pole 36slot) of stator for different tooth widths.

\section{Finite Element Analysis For Stator Tooth/Yoke Widths}

To validate the proposed method, FEA was conducted for 4 types of models: SPM distributed winding model 6pole 36slot and 8pole 48slot, IPM concentrated winding model 6pole 9slot and 10pole 15slot. For each model, we found the model that gives the most Back-EMF from FEA result.

Table 1 summarizes the number of armature series turns per phase and pole width and the materials of electrical steel. Since all of four models have the same stator, rotor outer diameter, number of turn per slot, and slot cross-sectional area, the model with a wider tooth width has a relatively narrower yoke width. No-load Back-EMF is computed based on 3000rpm at room temperature, when electric motor is operating, torque is analyzed for every 20Arms of input current ranging from 20Arms to 80Arms in case of distributed winding model and is similarly analyzed for every 50Arms of input current ranging from 50Arms to $200 \mathrm{Arms}$ in case of concentrated winding model. In addition, $\mathrm{Id}=0$ control method, a current vector current method, is applied. Figure 3 shows the shape and dimension of the review model each with the number of poles and slots. 


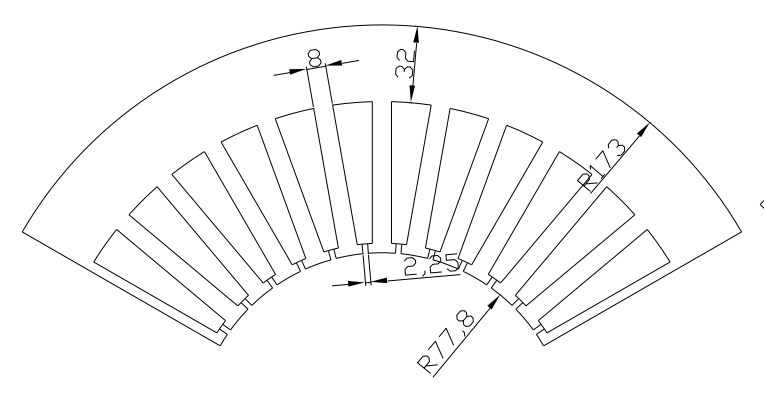

(a) 6pole 36slot

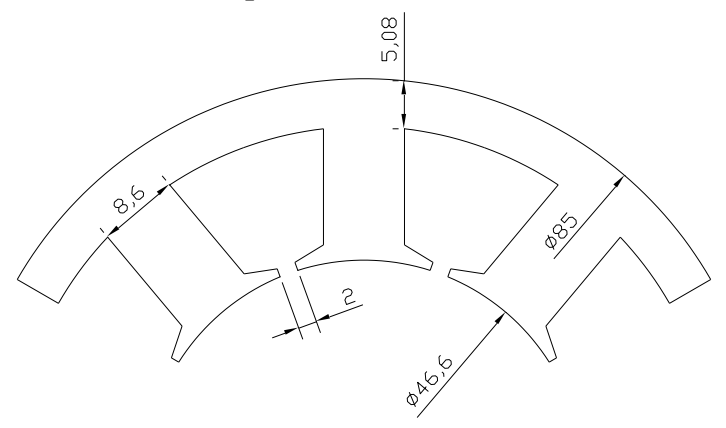

(c) 6pole 9slot

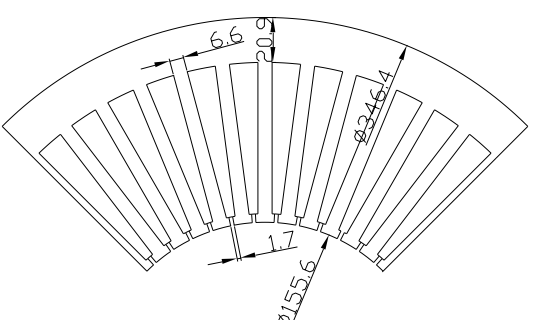

(b) 8pole 48slot

Fig. 3: Review model shape.

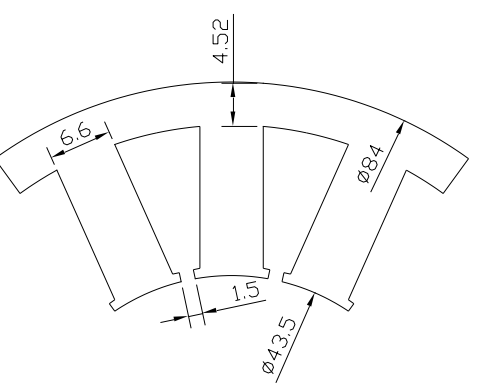

(d) 10pole 15slot

Table 1: Specification of models.

\begin{tabular}{|c|c|c|c|c|}
\hline \multirow{2}{*}{ Item } & \multicolumn{2}{|c|}{$\begin{array}{l}\text { Distributed } \\
\text { Winding(SPM) }\end{array}$} & \multicolumn{2}{|c|}{$\begin{array}{l}\text { Concentrated } \\
\text { Winding(IPM) }\end{array}$} \\
\hline & $\begin{array}{l}\text { 6pole } \\
36 \text { slot }\end{array}$ & $\begin{array}{l}\text { 8pole } \\
48 \text { slot }\end{array}$ & $\begin{array}{l}\text { 6pole } \\
\text { 9slot }\end{array}$ & $\begin{array}{l}\text { 10pole } \\
\text { 15slot }\end{array}$ \\
\hline $\begin{array}{l}\text { Stator/rotor } \\
\text { outer } \\
\text { diameter }[\mathrm{mm}]\end{array}$ & \multicolumn{2}{|c|}{$356.4 / 153.6$} & \multicolumn{2}{|l|}{$85 / 45$} \\
\hline $\begin{array}{l}\text { Stack length } \\
{[\mathrm{mm}]}\end{array}$ & \multicolumn{4}{|l|}{50} \\
\hline Series turns per phase & 60 & 120 & 10 & 10 \\
\hline $\begin{array}{l}\text { Residual flux density } \\
{[\mathrm{T}]}\end{array}$ & \multicolumn{4}{|l|}{1.4} \\
\hline $\begin{array}{l}\text { Magnetic core } \\
\text { material }\end{array}$ & \multicolumn{4}{|c|}{$50 \mathrm{PN} 470$} \\
\hline Slot area $\left[\mathrm{mm}^{2}\right]$ & 679.0 & 614.6 & 163.5 & 89.6 \\
\hline
\end{tabular}

The no-load Back-EMF and load torque of distributed winding and concentrated winding review model, each with different number of poles and slots, is analyzed using FEM for different tooth and yoke widths. Figure 4 shows the FEA result of no-load Phase back-EMF and load torque changes in the 6pole 36slot model for tooth and yoke width changes.

As shown in Table 2, the maximum Back-EMF and maximum torque were observed for tooth width with 9.7[mm] for distributed winding 6pole 36slot model, tooth width with $7.2[\mathrm{~mm}]$ for 8pole 48slot model, $9.0[\mathrm{~mm}]$ concentrated winding 6pole 9slot mode, $7.0[\mathrm{~mm}]$ for 10pole $15 \mathrm{slot}$ model. This means that tooth/yoke width at maximum no-load Back-EMF is equal to tooth/yoke width at maximum load torque.

Table 3 compares the tooth width obtained using FEA on each of review model, distributed winding model and concentrated winding model, and the proposed equivalent magnetic circuit of stator. It is shown that the tooth widths obtained using FEA and the proposed method are almost the same. 

(a) Phase back EMF
(b) Load torque

Fig. 4: Phase back EMF and load torque(6pole 36slot) for stator tooth widths.

Table 2: Tooth width to maximize back-EMF and load torque (FEA).

\begin{tabular}{|c|c|c|c|}
\hline \multicolumn{2}{|c|}{ Pole/slot } & $\begin{array}{c}\text { Tooth width } \\
\text { to } \\
\text { maximize } \\
\text { back-EMF } \\
\text { [mm] }\end{array}$ & $\begin{array}{c}\text { Tooth width to } \\
\text { maximize } \\
\text { load torque } \\
\text { [mm] }\end{array}$ \\
\hline \multirow{5}{*}{ Distributed winding } & $\begin{array}{c}\text { 6pole } \\
\text { 36slot }\end{array}$ & 9.7 & 9.7 \\
\cline { 2 - 4 } & $\begin{array}{c}\text { 8pole } \\
\text { 48slot }\end{array}$ & 7.2 & 7.2 \\
\hline \multirow{2}{*}{$\begin{array}{c}\text { Concentrated } \\
\text { winding }\end{array}$} & $\begin{array}{c}\text { 6pole } \\
\text { 9slot }\end{array}$ & 9.0 & 9.0 \\
\cline { 2 - 5 } & $\begin{array}{c}\text { 10pole } \\
15 \text { slot }\end{array}$ & 6.8 & 6.8 \\
\hline
\end{tabular}

Table 3: Comparison of FEA and EMC.

\begin{tabular}{|c|c|c|c|}
\hline \multicolumn{2}{|c|}{ Pole/slot } & $\begin{array}{l}\text { Optimized } \\
\text { tooth width } \\
\text { _FEA [mm] }\end{array}$ & $\begin{array}{c}\text { Optimized } \\
\text { tooth width } \\
\text { EMC } \\
{[\mathrm{mm}]}\end{array}$ \\
\hline \multirow{2}{*}{$\begin{array}{l}\text { Distributed } \\
\text { winding }\end{array}$} & $\begin{array}{l}\text { 6pole } \\
\text { 36slot }\end{array}$ & 9.7 & 9.7 \\
\hline & $\begin{array}{l}\text { 8pole } \\
\text { 48slot }\end{array}$ & 7.2 & 7.2 \\
\hline \multirow{2}{*}{$\begin{array}{c}\text { Concentrate } \\
\mathrm{d} \\
\text { winding }\end{array}$} & $\begin{array}{l}\text { 6pole } \\
\text { 9slot }\end{array}$ & 9.0 & 8.8 \\
\hline & $\begin{array}{l}\text { 10pole } \\
15 \text { slot }\end{array}$ & 6.8 & 6.6 \\
\hline
\end{tabular}

\section{Tooth Width/Yoke Width Determination Considering Armature Reaction}

Using the equivalent magnetic circuit of stator, tooth width and yoke width were determined. But the method used previously assumes no-load, and therefore, in case of the model with large armature reaction, tooth and yoke width that maximize the load torque may change. To check if the method applies to this case, we compared tooth and yoke widths that 
maximize load torque for traction electric motor which has a large armature reaction and that minimize magnetic resistance of stator considering armature reaction. Also, we compared results of FEA and the proposed EMC analysis to check the validity of the proposed equivalent magnetic circuit of stator. Figure 5 and Table 4 show the shape, dimension and specification of stator and rotor of continuous rated power $5 \mathrm{~kW}$ traction electric motor.

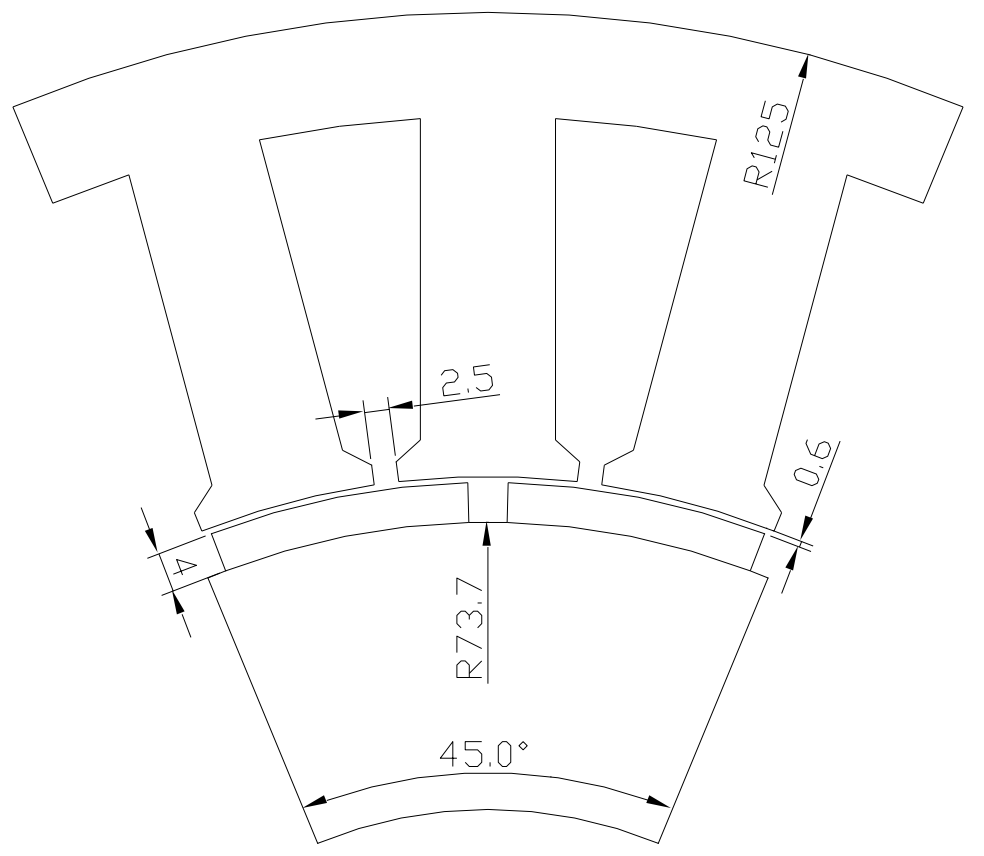

Fig. 5: Review model shape.

Table 4: Specification of model.

\begin{tabular}{|l|l|}
\hline Item & $\begin{array}{l}\text { 16pole 24slot } \\
\text { (Concentrated winding, } \\
\text { IPM) }\end{array}$ \\
\hline $\begin{array}{l}\text { Stator/rotor outer } \\
\text { diameter [mm] }\end{array}$ & $250 / 155.4$ \\
\hline Stack length [mm] & 40 \\
\hline Series turns per phase & 42 \\
\hline $\begin{array}{l}\text { Residual flux } \\
\text { density [T] }\end{array}$ & 1.4 \\
\hline $\begin{array}{l}\text { Magnetic core } \\
\text { material }\end{array}$ & $35 \mathrm{PN} 230$ \\
\hline Slot area [mm $\left.{ }^{2}\right]$ & 391 \\
\hline
\end{tabular}

The stator was assumed to have outer diameter of $250 \mathrm{~mm}$, stack length of $40 \mathrm{~mm}$, residual flux density $1.4 \mathrm{~T}$ for room temperature. For the proposed traction electric motor model, under the same slot area constraint, FEA was conducted to analyze load torque change for tooth/yoke width change, and tooth/yoke width for maximum load torque was found. Figure 6 demonstrates this result. The maximum load torque was shown for tooth width with $14.8 \mathrm{~mm}$.

In general, if either tooth or yoke has excessively large tooth magnetic resistance, the total magnetic resistance of stator increases and resulting load torque decreases. In that case, the flux density of either of tooth and yoke increases. We then studied how flux density and load torque are related. Figure 7 shows the change of flux density waveform on tooth and yoke as rotor rotates. For each tooth width, the flux density waveform is analyzed. As indicated in the figure, with the increase in tooth width, yoke width decreases, and consequently, flux density on the tooth reduces and that on the yoke increases. 


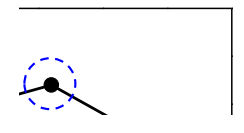

Fig. 6: Variation of load torque with tooth width.
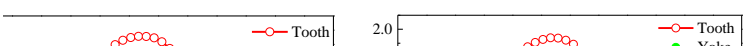
(a) Tooth width $13.8 \mathrm{~mm}$
(b) Tooth witdh $14.4 \mathrm{~mm}$
(c) Tooth width $14.8 \mathrm{~mm}$
(d) Tooth width $15.2 \mathrm{~mm}$
Fig. 7: Flux density waveform on tooth and yoke.

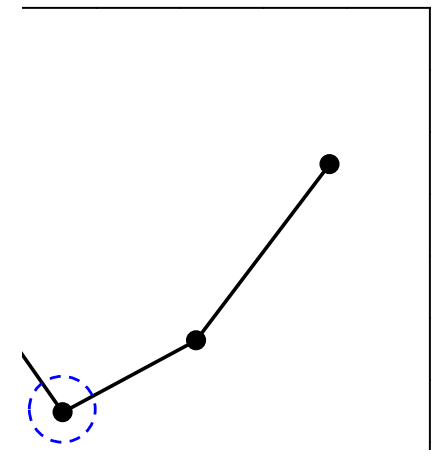

Fig. 8: Maximum value of flux density fundamental wave on tooth and yoke. Fig. 9: Variation of magnetic resistance of stator with tooth width.

In Figure 8, for tooth and yoke width changes, the trend of change in tooth fundamental waveform maximum value of flux density using FFT(Fast Fourier Transform) on tooth and yoke flux density waveform observed in Figure 7. As in Figure 7 , tooth width increases with decrease in yoke width, and this causes the maximum value of fundamental waveform of flux density on tooth to decrease and that of yoke to increase. The tooth width with maximum load torque using FEA was $14.8 \mathrm{~mm}$, and this is close to the value that flux densities of tooth and yoke converge to each other. This shows that maximum load torque was observed for the tooth and yoke widths that have similar flux density values. Using the proposed tooth and yoke width determination method, we found the tooth width that minimizes the magnetic resistance of stator for traction electric motor. 
Figure 9 shows the stator magnetic resistance change for the tooth/yoke width change in traction electric motor. Magnetic resistance of stator in Figure 9 was computed using the proposed equivalent magnetic circuit. As in the figure, tooth width with minimum magnetic resistance of stator was $14.4 \mathrm{~mm}$, and this was slightly different from the width found by FEM: $14.8 \mathrm{~mm}$. This shows that the application of proposed stator equivalent magnetic circuit may be limited in case of electric motors with significant amount of armature reaction. To resolve the problem, equivalent magnetic circuit design needs to consider the electric motor seen from the stator side.

Figure 10 describes the equivalent magnetic circuit of stator seen from the stator side. Assuming air-gap and rotor region as magnetic equipotential region, we form the corresponding area as a short circuit. For simplification of calculation, we replace the $\mathrm{Y}$-shaped wiring in the center of the circuit to the $\Delta$-shaped wiring. Then we calculate magnetic resistance of stator seen from a single magnetomotive force. In Figure 10, equivalent magnetic circuit of stator is equivalent magnetic circuit corresponding to a period of electric motor flux density distribution and Ry3 is magnetic resistance of yoke corresponding to the boundary between the periods.

Figure 11 shows stator load torque change using FEA, and magnetic resistance change using equivalent magnetic circuit of stator seen from the stator for the tooth width changes. As in the previous, for the same slot area, the tooth width changes with yoke width. As implied in Figure 11, tooth width that gives the minimal magnetic resistance of stator is $14.8 \mathrm{~mm}$, the same value obtained using FEA. Thus, when seen from the stator side, tooth width with minimal magnetic resistance of stator coincides with the result confirmed by FEA.

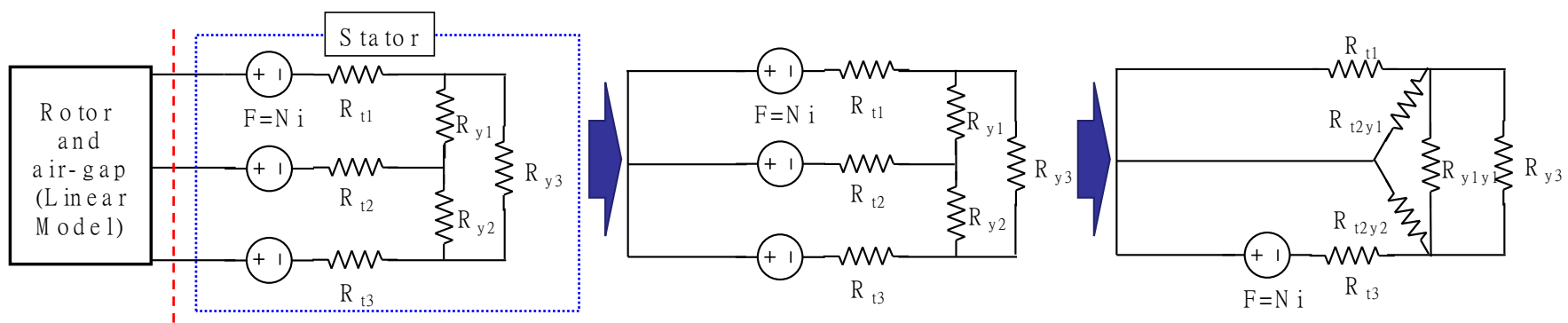

Fig. 10: Equivalent magnetic circuit of stator.

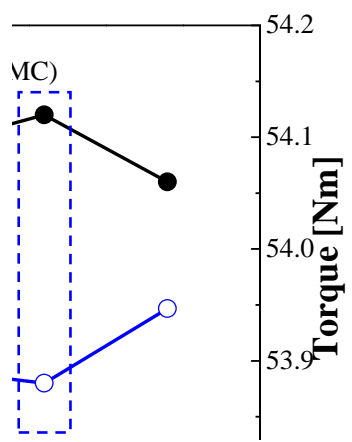

Fig. 11: Variation of equivalent magnetic resistance with tooth width.

\section{Conclusion}

Compared to FEA, it is much simpler to use the equivalent magnetic circuit to find the optimal tooth and yoke width: the width minimized the magnetic resistance of stator. In this study, we proposed equivalent magnetic circuit of stator to calculate the tooth and yoke width that maximize no-load Back-EMF and load torque. In addition, we compared the optimal teeth widths obtained using FEM and the proposed method. The similarities in the value confirmed the reliability and feasibility of the proposed stator equivalent magnetic circuit. Furthermore, we proposed a compensatory method for equivalent magnetic circuit of stator to account for armature reaction and confirmed the validity of the method by comparison with the FEA result. 


\section{Acknowledgements}

This work was supported by the Korea Evaluation Institute of Industrial Technology (Keit) grant funded by the Korea government (Ministry of Trade, Industry and Energy) (No. 10060295)

\section{References}

[1] L. Liu, W. Liu, and D. A. Cartes, "Permanent Magnet Synchronous Motor Parameter Identification using particle Swarm Optimization,” International Journal of Computational Intelligence Research, vol. 4, no. 2, pp. 211-218, 2008.

[2] S.-B. Lim, H. Kwon, S.-Y. Kwon, S. Choi, S.-H. Baek, and J. Lee, "Permanent Magnet overhang Effect in Permanent Magnetic Actuator Using 3 Dimension Equivalent Magnetic Circuit network Method," KIEE International Transactions on Electrical Machinery and Energy Conversion System, vol. 5-B, no. 2, pp. 123 128, 2005.

[3] J.-Y. Lee, S.-H. Lee, G.-H. Lee, J.-P. Hong, and J. Hur, "Determination of Parameters Considering Magnetic Nonlinearity in and Interior Permanent Magnet Synchronous motor," IEEE Trans. Magn., vol. 42, no. 4, pp. 1303-1306, 2006.

[4] Z. Q. Zhu, Y. Pang, D. Howe, S. Iwasaki, R. Deodhar, and A.Pride, "Analysis of Electromagnetic Performance of FluxSwitching Permanent-Magnet Machines by Nonlinear Adaptive Lumped Parameter Magnetic Circuit Model, "IEEE Trans. Magn., vol. 41, no. 11, pp. 4277-4287, 2005.

[5] A. H. Isfahani and S. Sadeghi, "Designof a Permanent Magnet Synchronous Machine for the Hybrid Electric Vehicle," International Journal of Electrical, Computer, and Systems Engineering, vol. 2, no. 1, 2008.

[6] L. Sang-Ho, K. Soon-O, L. Jeong-Jong, and H. Jung-Pyo, "Characteristic Analysis of Claw-Pole Machine Using Improved Equivalent Magnetic Circuit," IEEE Trans. Magn., vol. 45, no. 10, pp. 4570-4573, 2009.

[7] B. Sheikh-Ghalavand, S. Vaez-Zadeh, and A. H. Isfahani, "An improved Magnetic Equivalent Circuit Model for IronCore Linear Permanent-Magnet Synchronous Motors," IEEE Trans. Magn., vol. 46, no. 1, pp. 112-120, 2010.

[8] J. K. Kim, S. W. Joo, S. C. Hahn, and J. P. Hong, "Static characteristics of linear BLDC motor using equivalent magnetic circuit and finite element method," IEEE Trans. Magn., vol. 40, no. 2, pp. 742-745, 2004. 